\title{
Age Composition of the Spawning Stock Does Not Always Influence Recruitment
}

\author{
M. Joanne Morgan, Peter A. Shelton and John Brattey \\ Dept. of Fisheries and Oceans, PO Box 5667 \\ St. John's, NL, A1C 5X1, Canada
}

Morgan, M. J., P. A. Shelton, and J. Brattey. 2007. Age composition of the spawning stock does not always influence recruitment. J. Northw. Atl. Fish. Sci., 38: 1-12. doi:10.2960/J.v38.m584

\begin{abstract}
The concept that the age composition of the spawning stock is an important determinant of recruitment is wide-spread. However, the number of populations and species where this has actually been studied is fairly limited. This study explores the effect of age composition on recruitment in one American plaice (Hippoglossoides platessoides) and three Atlantic cod (Gadus morhua) populations. Both the effect of age diversity and the effect of the presence of first time spawners are explored. No consistent relationship between age composition of the spawning stock and recruitment was found for the populations examined. We conclude that age composition of the spawning stock may not be universally important. Further research is needed to explore how common the effect of age composition on recruitment is and under which conditions age composition exerts an important influence on recruitment.
\end{abstract}

Key words: age composition, Gadus morhua, Hippoglossoides platessoides, recruitment, reproductive potential.

(C) Crown, 2007

\section{Introduction}

The relationship between spawning stock biomass $(S S B)$ and recruitment is an essential element in the understanding of the population dynamics of fish stocks (Ricker, 1954). However, for most marine fish the stockrecruit (S-R) relationship remains poorly defined with large variability around any model predicted value. In part this may be because of the failure to account for changes in the characteristics of the fish making up the $S S B$. Variation in the condition of spawners can result in changes in fecundity and/or viability of eggs and larvae, or even in failure to spawn (Lambert and Dutil, 2000; Marshall et al., 1998; Marteinsdottir and Steinarssson, 1998; Rideout et al., 2000). Estimates of SSB often ignore variation in sex ratio and the proportion of fish that are mature at each age (Marshall et al., 1998; Kraus et al., 2002; Marshall et al., 2003). Failing to account for the above factors in the estimates of reproductive potential could obscure the $\mathrm{S}-\mathrm{R}$ relationship.

The age composition of the spawners may be important in determining the reproductive potential of fish stocks. The age composition of a fish population is not static, but shows considerable variation over time. Vari- ability in year-class strength and changes in mortality, either natural, or fishery induced, result in changes in the proportion of fish at each age in the population. The make up of the spawning portion of the population is affected by this variation, with the diversity of ages in the spawning stock and the proportion of repeat or first time spawners changing as the age composition varies. Characteristics of the individual fish making up the spawning stock will also impact the spawning stock's age composition. For example, age and size at maturity can show substantial variation (Hunt, 1996; Jørgensen, 1990; Morgan and Colbourne, 1999; Rijnsdorp, 1989) and the sex ratio can change over time and with age of fish (Kraus et al., 2002; Morgan and Brattey, 2005). Many of these changes are not random, but exhibit trends related to variation in mortality, growth and/or environmental conditions (Barot et al., 2005; Morgan and Colbourne, 1999; Olsen et al., 2004).

A spawning stock with a more diverse age composition has been found to produce more recruits, possibly through age dependent effects on spawning time and duration (Lambert, 1990; Marteinsdottir and Thorarinsson, 1998; O'Brien et al., 2003; Ottersen et al., 2006; Secor, 2000). Fish which spawn several batches of eggs 
over a prolonged spawning season and/or over a large spawning area, spread the risk of recruitment failure and thereby increase chances of successful recruitment (i.e. bet-hedging: Bulmer, 1985; Seger and Brockman, 1987; Shelton, 1992). In addition, a spawning stock with a more diverse age composition will often include the participation of a higher proportion of repeat spawning fish. Laboratory studies have indicated that for cod (Gadus morhua), first time spawners have much poorer spawning success than repeat spawners (Solemdal et al., MS 1995; Trippel, 1998). Cardinale and Arrhenius (2000b) found that in 3 populations of cod there was a strong influence of repeat spawners on the number of recruits produced. Marshall et al. (1998) also found that recruitment was higher in Arcto-Norwegian cod when there were more repeat spawning fish. In contrast, a large mesocosm study of cod reproduction, failed to find a difference in reproductive success between first time and repeat spawners (Clemmesen et al., 2003). Wigley (1999) found an effect of first time spawners on recruitment in haddock (Melanogrammus aeglefinus), but not for witch flounder (Glyptocephalus cynoglossus). Both the age diversity of the spawning stock and the proportion of repeat spawners will usually be higher for larger spawning stocks where mortality has not resulted in a truncated age distribution (Marteinsdottir and Thorarinsson, 1998; Trippel et al., 1997).

The sometimes contradictory results of these studies of the importance of repeat spawners and the small number of studies on the effects of age diversity of the spawning stock, suggests that the importance of age composition on stock reproductive potential is as yet unclear. Most studies have been on cod and only a handful of populations have been examined. In this study we explore the effect of age composition on reproductive potential in three populations of Atlantic cod and one population of American plaice (Hippoglossoides platessoides). Both the effect of age diversity and the presence of first time spawners were explored.

\section{Materials and Methods}

\section{Stock-recruit from Sequential Population Analyses}

Four populations of groundfish were examined; Northwest Atlantic Fisheries Organization (NAFO) Div. 2J3KL cod, Div. 3NO cod, Subdiv. 3Ps cod and Div. 3LNO American plaice (Fig. 1). SSB was produced for each population from numbers-at-age estimated using sequential population analysis (ADAPT; Gavaris, MS 1988), and weight-at-age sample estimates of the com- mercial catch (Brattey et al., MS 2004; Dwyer et al., MS 2005; Power et al., MS 2005; Shelton and Lilly, 2000). Data were available from 1962-2001 for 2J3KL cod, 1959-2003 for 3NO cod, 1977-2004 for 3Ps cod and from 1960-2003 for 3LNO American plaice. Proportion mature-at-age and proportion female-at-age were estimated for each cohort from RV sample data, by applying the methods described in Morgan and Brattey (2005). Recruitment $(R)$ was defined as the population model estimates of the beginning of year numbers alive at age 2 for the cod populations and at age 5 for American plaice, the youngest ages in the estimation. $S S B$ was calculated as:

$$
S S B_{y}=\sum_{a=i}^{j} N_{a, y} W_{a, y} M_{a, y} S R_{a, y}
$$

where $N_{a, y}$ is the population number-at-age $a$ in year $y$, $W_{a, y}$ the weight-at-age $a$ in year $y, M_{a, y}$ is the proportion mature-at-age $a$ in year $y, S R_{a, y}$ is the proportion femaleat-age $a$ in year $y$, and $a$ is the age from $i$ to $j$ (for $2 \mathrm{~J} 3 \mathrm{KL}$ $\operatorname{cod} i=2, j=20$; for 3LNO plaice $i=5, j=15+$; for $3 \mathrm{NO}$ $\operatorname{cod} i=2, j=12$; for 3Ps $\operatorname{cod} i=2, j=14$ ).

Two different measures of age diversity were examined for each stock. The first was the Shannon diversity index as applied by Marteinsdottir and Thorarinsson (1998),

$$
H_{y}=\frac{1}{n}\left(n \log (n)-\sum_{i=1}^{k} f_{i} \log \left(f_{i}\right)\right)
$$

where $n$ is the total number of mature females in all age groups, $f_{i}$ is the number of mature females aged $i$ and $k$ is the number of age groups. A higher $H$ indicates a more even distribution of spawners across age classes and is thought to enhance $R$.

The second measure of age diversity was the weighted mean age of the $S S B(M A)$, where mean age was calculated weighting by the $S S B$ at each age:

$$
M A_{y}=\frac{1}{S S B_{y}} \sum_{a=i}^{j} a S S B_{a, y}
$$

Higher $M A$ indicates a spawning population made up of a higher proportion of older females and is expected to enhance recruitment. 


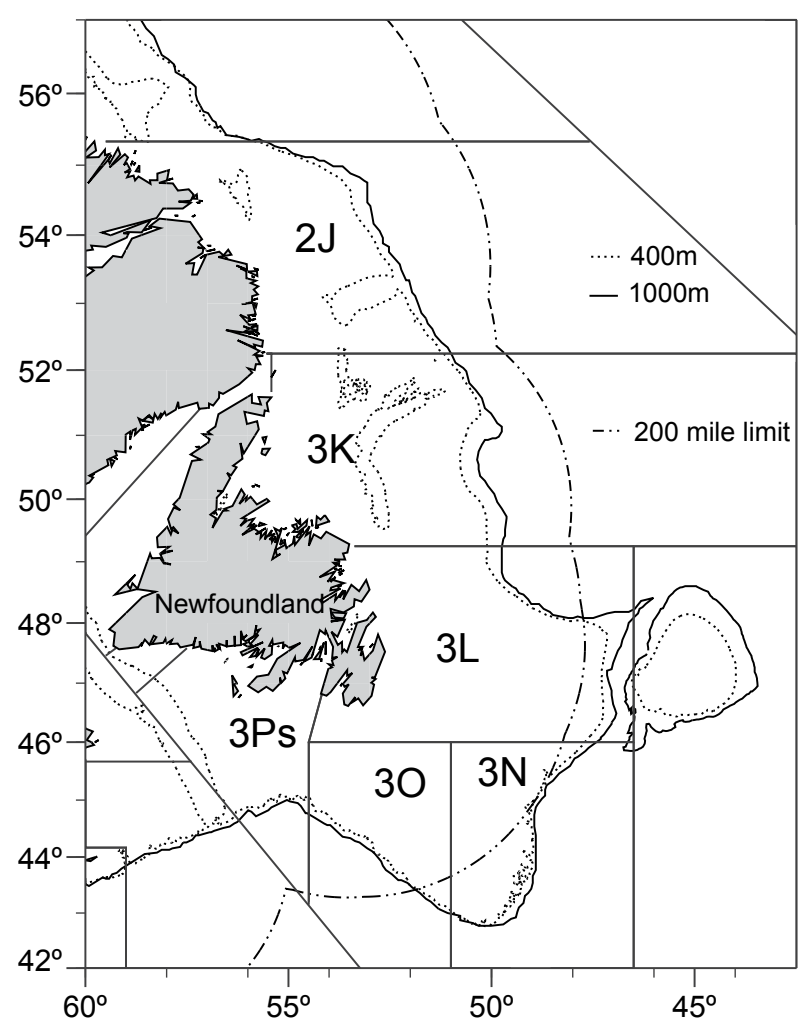

Fig. 1. Map of the study area showing the Northwest Atlantic Fisheries Organization Divisions used to define the populations.

Proportion of first time spawners $\left(P_{\text {first }}\right)$ in each year (y) was calculated assuming equal mortality on immature and adult fish:

$$
P_{\text {first }_{y}}=\frac{1}{S S B_{y}} \sum_{a=i}^{j} \frac{M_{a, y}-M_{a-1, y-1}}{M_{a, y}} S S B_{a, y}
$$

An $S S B$ with a higher number of first time spawners will have a higher $P_{\text {first }}$. This will occur when there are trends to maturation at a younger age and/or when there is a large year-class entering the $S S B$. High $P_{\text {first }}$ is thought to result in lower recruitment.

The correlation between these three factors $(H, M A$ and $\left.P_{\text {first }}\right)$ and $S S B$ was explored for each stock. Also the correlation between these factors and between these factors and $R$ was explored.

Despite the noise in the data, $S S B$ is expected to explain some of the variability in $R$ (Brodziak et al., 2001; Myers and Barrowman, 1996). This is an underlying assumption of this study and the effect of age composition was examined as an explanation for variation in $R$ not explainable by variation in $S S B$. This was explored using LOWESS smoothers which allowed the relationship between $S S B$ and $R$ to be described without imposing any particular functional form. It was assumed, that except for the possible effects of density dependence, $R$ would generally not show a decrease with increasing $S S B$. Therefore the smoothing window was chosen to allow density dependence but was the smallest window that otherwise resulted in a monotonic function between $S S B$ and $R$. This was done to try to prevent over fitting of the data. The residuals from the smoothed fit were examined with respect to $H, M A$ and $P_{\text {first }}$ to determine if there was any relationship between the measures of age composition and $R$ after the effect of $S S B$ on $R$ was removed. As a further test, the relationship between $H, M A$ and $P_{\text {first }}$ and $R$ was explored for areas of the stock-recruit scatter where there was a small range in $S S B$ and a large range in $R$, to determine if the variation in $R$ was related to any of these factors.

\section{Stock-recruit from Survey}

The age structured model (ADAPT) estimates of numbers-at-age, including $R$, are determined by the underlying assumptions, the age-disaggregated survey index and by the commercial catch-at-age. Model misspecification and measurement error in the data will result in errors in the estimated population numbers-at-age and may affect any attempt to examine the factors determining $R$. The same analyses were conducted using research vessel (RV) data only (spring survey data for $3 \mathrm{NO}$ cod and 3LNO American plaice, autumn for 2J3KL cod, and spring and winter for 3Ps cod). These data tend to have large year effects resulting from measurement and process error. $S S B, H, M A$ and $P_{\text {first }}$ were calculated, as above but using the population numbers-at-age as measured from RV catches. One of the drawbacks of this approach compared to using model estimates is that there is no accounting for the year effects inherent in the data. In order to partly address this, estimates of $R$ were obtained from a cohort strength model:

$$
\log \left(I_{a, y}\right)=\mu+C_{c}+A_{a}+\varepsilon_{a, y}
$$

where $\mu=$ intercept, $a=$ age subscript (ages 2 to 3 for the cod populatons, 3 to 5 for American plaice), $c=$ year-class subscript, $I=$ Index (Abundance in 000s), $C=$ year-class effect, $A=$ Age effect, and $\varepsilon=$ error term.

A second disadvantage of time series constructed from research vessel survey data is a shorter number of years of data for most of the populations compared to 
ADAPT which can hindcast population numbers prior to the commencement of the RV series. For 2J3KL cod stock recruit pairs from RV surveys were available for 1982-2001, for 3NO cod 1975-2001 and for 3LNO American plaice 1985-2000. For 3Ps cod, the time series from surveys is actually longer than from ADAPT, with stock recruit pairs available for 1972-2001. Relationships between $H, M A, P_{\text {first }}$ and $S S B$, between each pair of factors and between the factors and $R$ were examined. A LOWESS smoother was fitted to the stock recruit data for each population, in the same manner as for the analyses of SPA estimates. However, there did not seem to be a relationship between $S S B$ and $R$ for $3 \mathrm{NO}$ cod, so for this population the mean recruitment was used for computing the residuals. The residuals from the smoothed fit (or from the mean in the case of $3 \mathrm{NO}$ cod) were examined for effects of $H, M A$ and $P_{\text {first }}$ to determine if there was any relationship between the measures of age composition and $R$ after first accounting for the effect of $S S B$ on $R$. The relationship between the factors and areas of the stock-recruit scatter where there was a small range in $S S B$ and a large range in $R$, was not explored given the generally short time series of S-R for the RV survey data.

\section{Results}

\section{Stock-recruit from Sequential Population Analyses (ADAPT)}

Each population showed substantial variation in $H$, $M A$ and $P_{\text {first }}$ with both shorter and longer term trends (Fig. 2). Long term trends were evident for 2J3KL cod and 3LNO American plaice where $M A$ showed a long period of steep decline, before increasing again. The declines in $M A$ occurred as $S S B$ decreased. Although quite variable, there was also a long term decline in $P_{\text {first }}$ in $3 \mathrm{NO}$ cod and perhaps 3Ps cod. There is some indication of an increase in $H$ and $M A$ in all the populations when fishing moratoria were instituted in the mid 1990's. The decline in $P_{\text {first }}$ in recent years for $3 \mathrm{NO}$ cod is likely the result of the very low $R$ in recent years in that population. Overall, however, there was no consistency in the correlation between these factors and SSB (Table 1). Only half of the correlations were significant and the direction of the correlation was not always as predicted. For example, it was thought that $P_{\text {first }}$ should be negatively correlated with $S S B$ yet it was positively correlated for $3 \mathrm{NO}$ cod. $H$ and $M A$ were expected to be positively correlated
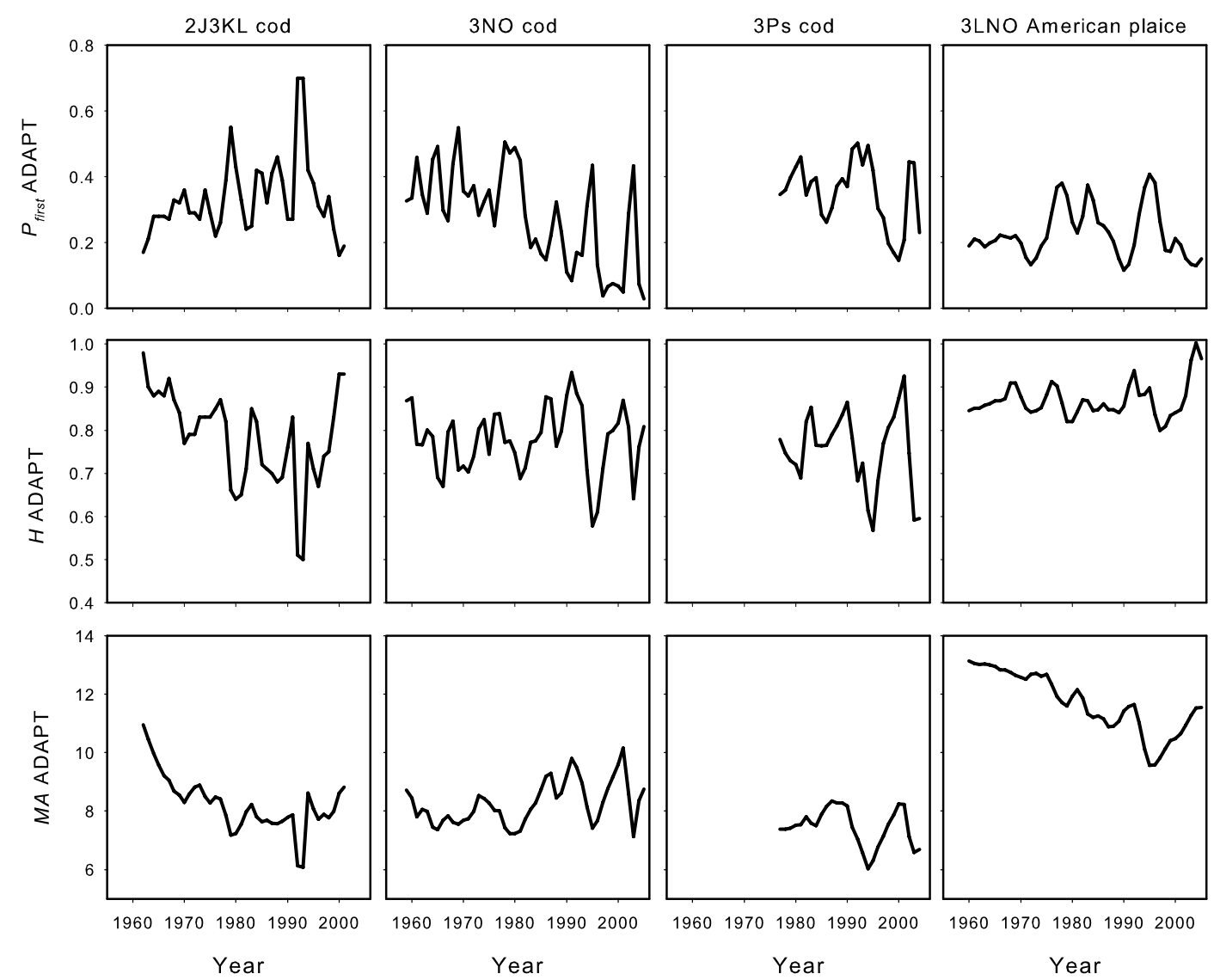

Fig. 2. Time series of measures of age composition from ADAPT examined for $2 \mathrm{~J} 3 \mathrm{KL}$ cod, $3 \mathrm{NO}$ cod, $3 \mathrm{Ps}$ cod, and 3LNO American plaice. 
Table 1. Results of correlation analyses for each factor (proportion of first time spawners $\left(P_{\text {first }}\right)$, Shannon diversity index $(H)$, weighted mean age of the $S S B(M A)$ ) with $S S B$ for each stock. The correlation coefficient and $p$ value are given. NS represents tests that were not significant at the 0.05 level. Results are from estimates derived using ADAPT and from RV survey data.

\begin{tabular}{|c|c|c|c|c|c|c|}
\hline & \multicolumn{2}{|c|}{$P_{\text {first }}$} & \multicolumn{2}{|c|}{$H$} & \multicolumn{2}{|c|}{$M A$} \\
\hline & $r$ & $p$ & $r$ & $p$ & $r$ & $p$ \\
\hline \multicolumn{7}{|l|}{ ADAPT } \\
\hline $2 \mathrm{~J} 3 \mathrm{KL}$ cod & -0.28 & 0.08 & 0.47 & 0.002 & 0.71 & $<0.001$ \\
\hline $3 \mathrm{NO} \operatorname{cod}$ & 0.38 & 0.008 & -0.06 & NS & -0.27 & NS \\
\hline 3Ps cod & -0.61 & 0.001 & 0.38 & NS & 0.48 & 0.01 \\
\hline 3LNO American plaice & -0.12 & NS & -0.12 & NS & 0.77 & $<0.001$ \\
\hline \multicolumn{7}{|l|}{ RV } \\
\hline $2 \mathrm{~J} 3 \mathrm{KL} \operatorname{cod}$ & -0.72 & $<0.001$ & 0.57 & 0.003 & 0.86 & $<0.001$ \\
\hline $3 \mathrm{NO} \operatorname{cod}$ & -0.20 & 0.31 & 0.16 & NS & 0.27 & NS \\
\hline 3Ps cod & -0.24 & NS & -0.09 & NS & -0.12 & NS \\
\hline 3LNO American plaice & -0.25 & NS & 0.29 & NS & 0.51 & 0.02 \\
\hline
\end{tabular}

with $S S B$ but the direction of the correlation was negative in 3 of 8 cases.

There were significant correlations between all of the age composition factors (Table 2). $P_{\text {frrst }}$ was generally negatively correlated with $H$ and $M A$, which were positively correlated with each other. There was little consistency however, across populations in the correlation of these factors with $R$. All 3 were significantly correlated with $R$ in $2 \mathrm{~J} 3 \mathrm{KL}$ cod, while none were for 3 Ps cod. $M A$ was positively correlated with $R$ in $3 \mathrm{LNO}$ American plaice but negatively correlated with $R$ in $3 \mathrm{NO}$ cod. Finally, $P_{\text {first }}$ was positively correlated with $R$ in $3 \mathrm{NO}$ cod when a negative correlation was expected.

All populations showed an increase in recruitment with increasing SSB (Fig. 3). For each population there was considerable scatter about the LOWESS smoother fitted to the S-R data, with a wide range in recruitment residuals across a narrow range in $S S B$. For $2 \mathrm{~J} 3 \mathrm{KL}$ cod, SSB ranging from 176 000-214 $000 \mathrm{t}$ gave rise to $R$ varying from $86-560$ million. For $3 \mathrm{NO}$ cod, the $S S B$ from 30 000-42 000 t produced $R$ ranging from 6-252 million individuals. For 3Ps cod, SSB ranging from $13000-18000$ t gave $R$ from 13-78 million. For 3LNO American plaice a range of SSB from 60000-100 $000 \mathrm{t}$ gave $R$ ranging from 55-232 million.

In regions of $S S B$ where there is large variation in $R$ across a small range of SSB (see above), there is little indication of a relationship between $R$ and any of the factors (Table 3 ). The only significant correlation is between $R$ and $M A$ for 3LNO American plaice. The relationship between $R$ and $P_{\text {first }}$ approached significance for $3 \mathrm{NO}$ cod.

There was only one significant correlation between the residuals from $R$ predicted by the LOWESS smoother and $P_{\text {frist }}, H$ or $M A$. This was for $3 \mathrm{NO}$ cod for the correlation between the residuals and $P_{\text {frist }}$ (Table 3). The relationship between the residuals and $M A$ approached significance for 3LNO American plaice. Overall, there is little indication of any relationship between these factors and $R$, once the effect of $S S B$ on $R$ is accounted for.

\section{Stock-recruit from Survey}

Both long and short term variation in $P_{\text {frrst, }}, M A$ and $H$ were also evident in the indices derived from RV survey data (Fig. 4). $H$ and $M A$ declined and then increased in 3LNO American plaice with changes in $M A$ being correlated with $S S B$ (Table 1). There was a long term increasing trend in $P_{\text {first }}$ and decrease in $M A$ for $2 \mathrm{~J} 3 \mathrm{KL}$ cod. For $3 \mathrm{NO}$ cod there was a decline in $P_{\text {frist }}$ over most of the time series. Long term trend was not evident in the 3Ps cod data.

Most populations showed some tendency for $R$ to increase with $S S B$, except for $3 \mathrm{NO}$ cod for which $R$ appeared to be independent of $S S B$ (Fig. 5). However, this was mostly an increase at the largest $S S B$ estimated, with $R$ being independent of $S S B$ at lower levels of SSB. As 

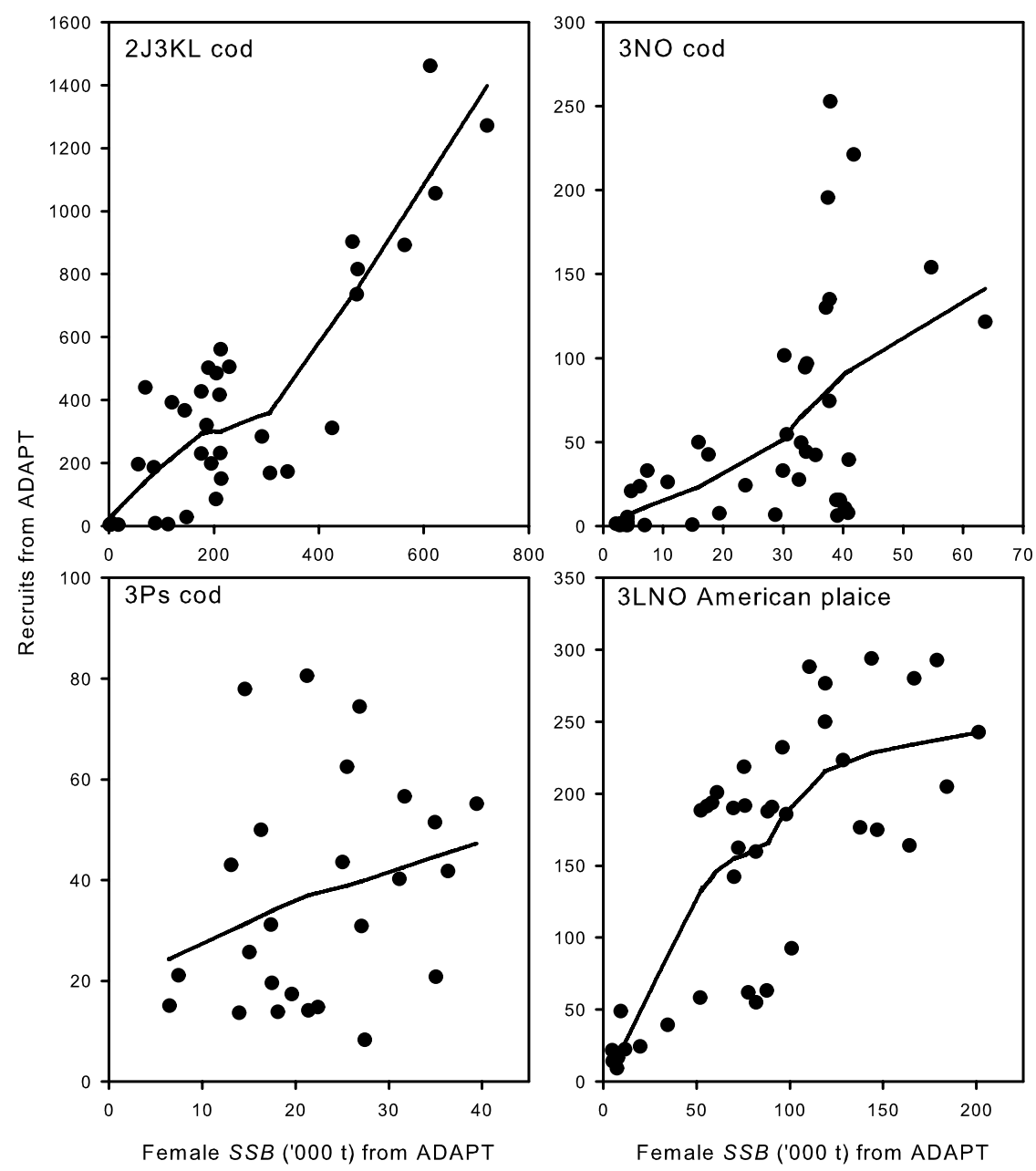

Fig. 3. Recruitment in millions and female spawning stock biomass $(S S B)$ in thousands of tons from sequential population analyses (ADAPT) for 2J3KL cod, 3NO cod, 3Ps cod, and 3LNO American plaice. The solid line shows the LOWESS smoother and the dots are the individual estimates.

with the results from ADAPT, there was no consistency across populations in the correlation between $P_{\text {frrst }}, H$, $M A$ and $S S B$, with only 4 of 12 tests being significant. The sign of the correlation coefficient was not always as predicted with the direction of the correlation for $H$ and $M A$ with SSB for 3Ps cod being negative (Table 1).

There was significant correlation between factors derived from RV survey data (Table 4). $P_{\text {frist }}$ was negatively correlated with $H$ and $M A$, while $M A$ and $H$ were positively correlated. There was only one significant correlation between the factors and $R$, this was a negative correlation between $M A$ and $R$ for 3 Ps cod.

The only significant relationship between the residuals from the estimated recruitment (either from smoother or mean recruitment in the case of $3 \mathrm{NO}$ cod) was for 3Ps cod with $M A$ and this was a negative relationship rather than a positive one as expected (Table 3). As with the analyses using estimates derived from SPA, there was little indication of any relationship between the factors and $R$ once the effect of $S S B$ had been accounted for.

\section{Discussion}

There was substantial variation in all three measures of age composition $\left(H, M A, P_{\text {frrst }}\right)$ for all four populations examined. This included both interannual variation and long and medium term trends. The clearest of the long term trends were for $2 \mathrm{~J} 3 \mathrm{KL}$ cod and $3 \mathrm{LNO}$ American plaice using estimates from ADAPT, where $M A$ showed a long period of steep decline, and then an increase in the most recent years. The variability in age composition can be attributed to the fact that all of these populations have 
Table 2. Results of correlation analyses between each factor (proportion of first time spawners $\left(P_{\text {first }}\right)$, Shannon diversity index $(H)$ and weighted mean age of the $S S B(M A)$ ), and between each factor and recruitment $(R)$ and with recruitment from selected sections of the $S / R$ scatter $\left(R_{\text {slices }}\right)$ for each stock. The correlation coefficient and $p$ value are given. NS represents tests that were not significant at the 0.05 level. Results are from estimates derived using ADAPT.

\begin{tabular}{|c|c|c|c|c|c|c|c|c|}
\hline & \multicolumn{2}{|r|}{$H$} & \multicolumn{2}{|c|}{$M A$} & \multicolumn{2}{|c|}{$R$} & \multicolumn{2}{|c|}{$R_{\text {slices }}$} \\
\hline & $r$ & $p$ & $r$ & $p$ & $r$ & $p$ & $r$ & $p$ \\
\hline \multicolumn{9}{|c|}{ 2J3KL cod } \\
\hline$P_{\text {first }}$ & -0.82 & $<0.001$ & -0.74 & $<0.001$ & -0.43 & $<0.01$ & -0.32 & NS \\
\hline$H$ & & & 0.86 & $<0.001$ & 0.59 & $<0.001$ & -0.27 & NS \\
\hline$M A$ & & & & & 0.76 & $<0.001$ & -0.02 & NS \\
\hline \multicolumn{9}{|c|}{$3 N O \operatorname{cod}$} \\
\hline$P_{\text {first }}$ & -0.40 & $<0.005$ & -0.80 & $<0.001$ & 0.43 & $<0.01$ & 0.42 & NS \\
\hline$H$ & & & 0.73 & $<0.001$ & -0.04 & NS & 0.08 & NS \\
\hline$M A$ & & & & & -0.37 & $<0.05$ & -0.34 & NS \\
\hline \multicolumn{9}{|c|}{ 3Ps cod } \\
\hline$P_{\text {first }}$ & -0.46 & $<0.05$ & -0.45 & $<0.05$ & 0.07 & NS & -0.55 & NS \\
\hline$H$ & & & 0.84 & $<0.001$ & -0.10 & NS & 0.10 & NS \\
\hline$M A$ & & & & & 0.15 & NS & 0.10 & NS \\
\hline \multicolumn{9}{|c|}{$\begin{array}{l}\text { 3LNO American } \\
\text { plaice }\end{array}$} \\
\hline$P_{\text {first }}$ & -0.15 & NS & -0.34 & $<0.05$ & -0.21 & NS & 0.15 & NS \\
\hline$H$ & & & 0.12 & NS & 0.06 & NS & -0.11 & NS \\
\hline$M A$ & & & & & 0.83 & $<0.01$ & 0.74 & $<0.005$ \\
\hline
\end{tabular}

Table 3. Results of correlation analyses for each factor (proportion of first time spawners $\left(P_{\text {frrs }}\right)$, Shannon diversity index $(H)$ and weighted mean age of the $S S B(M A)$ ), with the residuals from the LOWESS smoother of the stock recruit data. The correlation coefficient and $p$ value are given. NS represents tests that were not significant at the 0.05 level. Results are from estimates derived using ADAPT and from RV survey data.

\begin{tabular}{|c|c|c|c|c|c|c|}
\hline & \multicolumn{2}{|c|}{$P_{\text {first }}$} & \multicolumn{2}{|c|}{$H$} & \multicolumn{2}{|c|}{$M A$} \\
\hline & $r$ & $p$ & $r$ & $p$ & $r$ & $p$ \\
\hline \multicolumn{7}{|l|}{ ADAPT } \\
\hline $2 \mathrm{~J} 3 \mathrm{KL} \operatorname{cod}$ & -0.10 & NS & 0.05 & NS & 0.08 & NS \\
\hline $3 \mathrm{NO} \operatorname{cod}$ & 0.32 & $<0.05$ & 0.001 & NS & -0.28 & NS \\
\hline 3Ps cod & 0.25 & NS & -0.22 & NS & 0.003 & NS \\
\hline 3LNO American plaice & 0.16 & NS & 0.08 & NS & 0.29 & NS \\
\hline \multicolumn{7}{|l|}{ RV } \\
\hline $2 \mathrm{~J} 3 \mathrm{KL} \operatorname{cod}$ & 0.10 & NS & -0.16 & NS & -0.05 & NS \\
\hline $3 \mathrm{NO} \operatorname{cod}$ & 0.09 & NS & -0.05 & NS & -0.34 & NS \\
\hline 3Ps cod & -0.13 & NS & 0.03 & NS & -0.43 & $<0.05$ \\
\hline 3LNO American plaice & -0.01 & NS & -0.37 & NS & -0.26 & NS \\
\hline
\end{tabular}



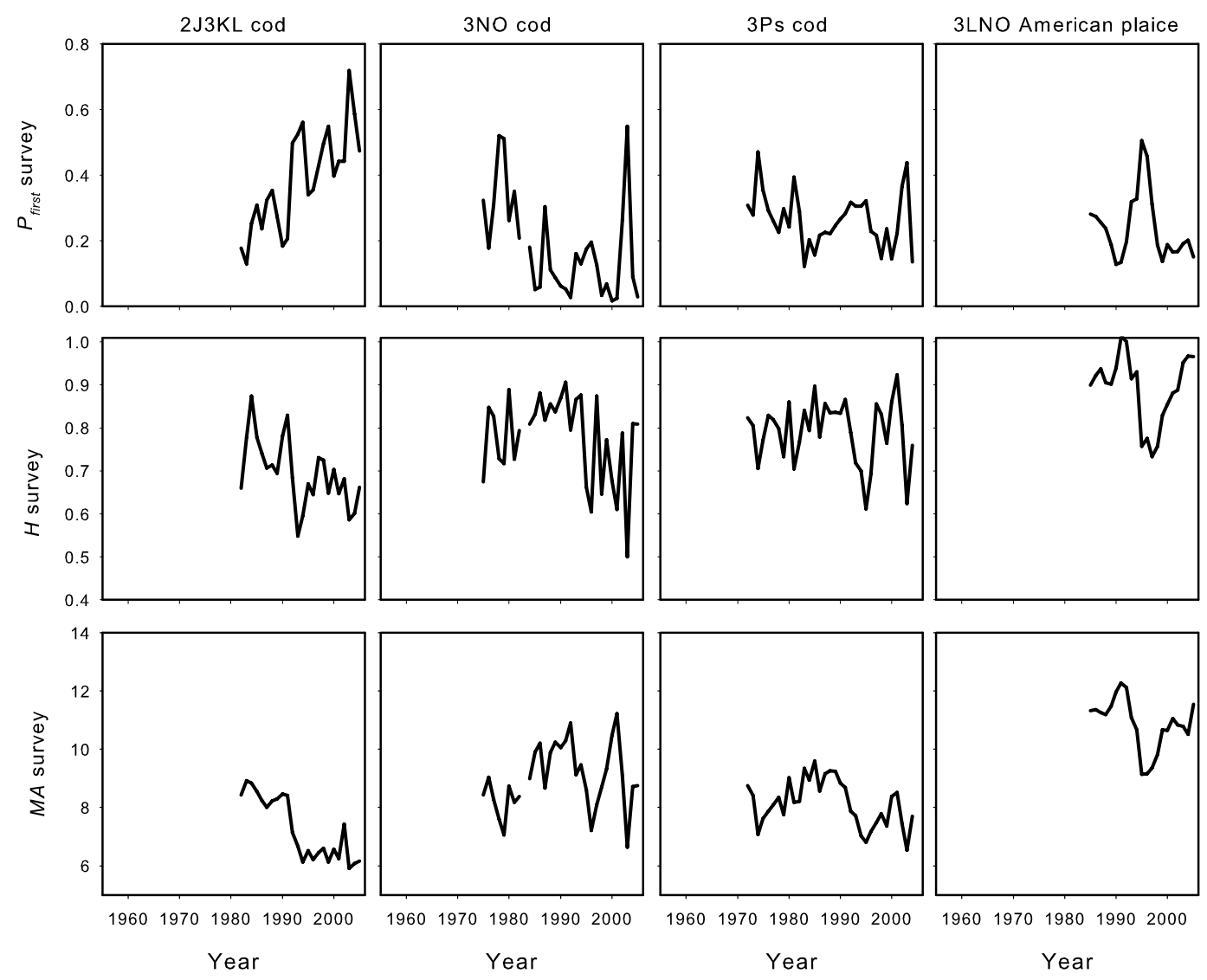

Fig. 4. Time series of measures of age composition from RV survey data examined for $2 \mathrm{~J} 3 \mathrm{KL}$ cod, $3 \mathrm{NO}$ cod, 3Ps cod, and 3LNO American plaice.

shown changes in age at maturity and sex ratio (Morgan and Brattey, 2005; Morgan and Colbourne, 1999) and have had their numbers at age impacted by fishing mortality and variable recruitment (Brattey et al., MS 2004; Dwyer et al., MS 2005; Power et al., MS 2005; Shelton and Lilly, 2000). It was expected that $P_{\text {frrst }}$ would increase as $S S B$ declined, while $H$ and $M A$ would decline at smaller $S S B$. However, variation in these factors was not consistent across populations and did not always change as predicted.

No consistent relationship was found between age composition of the spawning stock and recruitment for the four groundfish populations examined in this study. There was some indication from ADAPT estimates that $P_{\text {first }}$ may influence recruitment in $3 \mathrm{NO}$ cod and $M A$ might be important for $3 \mathrm{LNO}$ American plaice. Survey data indicated that there could be a negative relationship between $M A$ and $R$ for 3Ps cod. When the alpha level associated with significance was adjusted for the number of individual tests that were conducted, none of the tests proved to be significant. There is little evidence that age composition of the spawning stock plays a major role in recruitment in these populations.

The concept that the age composition of a spawning stock is an important determinant of $R$ is wide spread. However, the number of populations and species for which it has actually been studied is fairly limited. The impact of $H$ has only been explicitly examined for Icelandic cod (Marteinsdottir and Thorarinsson, 1998), Georges Bank cod (O'Brien et al., 2003), and ArctoNorwegian cod (Ottersen et al., 2006), and Chesapeake Bay striped bass (Morone saxatilis) (Secor, 2000). All found increased recruitment with a more diverse age composition of the SSB. For the cod populations examined in the present study, the range in $H$ was at least as great as that found for the previous studies, and the populations have exhibited substantial variation in $S S B$. Yet there was little indication of any effect of $H$ on $R$. Marshall et al. (1998) speculated that part of the effect of $H$ on $R$ could be the result of differences in sex ratioat-age (or length) where the proportion female increases with age or size. In a population at low SSB with low 


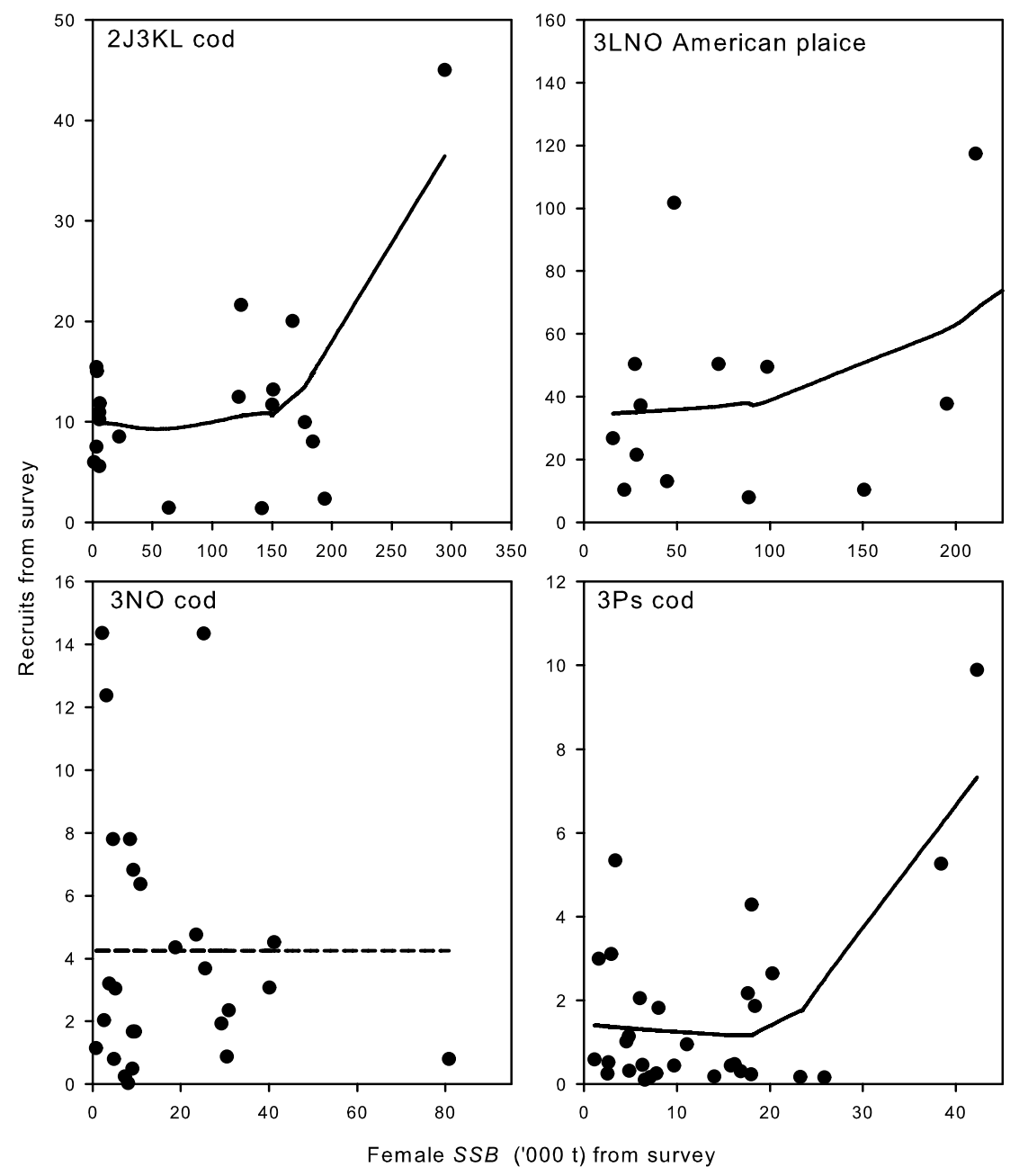

Fig. 5. Recruitment in millions and female spawning stock biomass $(S S B)$ in thousands of tons from research vessel survey data for $2 \mathrm{~J} 3 \mathrm{KL}$ cod, $3 \mathrm{NO}$ cod, $3 \mathrm{Ps}$ cod, and 3LNO American plaice. The solid line shows the LOWESS smoother, the dashed line is the mean for $3 \mathrm{NO}$ cod, and the dots are the individual estimates.

$H$ there are often fewer older (larger) fish and therefore proportionately fewer females. Among adults, older fish tend to have a higher proportion female both because males mature at a younger age and because there can be differential mortality on the sexes. In the present study, sex ratio is incorporated into the calculation of SSB and so some of the effect may be already taken into account. However, Secor (2000) examined the effect of age diversity of female striped bass (i.e. after taking sex ratio into account) and did find a positive effect on recruitment.

Our study also examined age composition through $M A$. A high $M A$ indicates an $S S B$ composed mainly of older females. There was substantial variation in $M A$, especially for $2 \mathrm{~J} 3 \mathrm{KL}$ cod and $3 \mathrm{LNO}$ American plaice, but little indication of a significant impact of $M A$ on $R$. There was a positive effect of $M A$ on $R$ for 3LNO American plaice for data from ADAPT when a section of the stock recruit scatter was examined that showed high variability in $R$ across a small range in SSB. However there was little other evidence of a positive effect of $M A$ on recruitment.

First time spawners are thought to have lower reproductive success than repeat spawning fish (Solemdal et al., MS 1995; Trippel, 1998). $R$ has been found to be enhanced by an increased proportion of repeat spawners in several populations of cod and one population of haddock (Cardinale and Arrhenius, 2000b; Marshall et al., 1998; Wigley, 1999). However, other studies have found no effect (Clemmesen et al., 2003; Wigley, 1999). Our results suggest that $P_{\text {first }}$ might be important only in one 
TABLE 4. Results of correlation analyses between each factor (proportion of first time spawners $\left(P_{\text {frrst }}\right)$, Shannon diversity index $(H)$ and weighted mean age of the $S S B(M A)$ ), and between each factor and recruitment $(R)$ for each stock. The correlation coefficient and $p$ value are given. NS represents tests that were not significant at the 0.05 level. Results are from estimates derived using RV survey data.

\begin{tabular}{|c|c|c|c|c|c|c|}
\hline & \multicolumn{2}{|c|}{$H$} & \multicolumn{2}{|c|}{$M A$} & \multicolumn{2}{|c|}{$R$} \\
\hline & $r$ & $p$ & $r$ & $p$ & $r$ & $p$ \\
\hline \multicolumn{7}{|c|}{ 2J3KL cod } \\
\hline$P_{\text {first }}$ & -0.73 & $<0.001$ & -0.85 & $<0.001$ & -0.09 & NS \\
\hline$H$ & & & 0.75 & $<0.001$ & -0.02 & NS \\
\hline$M A$ & & & & & 0.16 & NS \\
\hline \multicolumn{7}{|c|}{$3 N O \operatorname{cod}$} \\
\hline$P_{\text {first }}$ & -0.35 & NS & -0.81 & $<0.001$ & 0.09 & NS \\
\hline$H$ & & & 0.40 & $<0.05$ & -0.05 & NS \\
\hline$M A$ & & & & & -0.34 & NS \\
\hline \multicolumn{7}{|c|}{ 3Ps cod } \\
\hline$P_{\text {first }}$ & -0.58 & $<0.001$ & -0.54 & $<0.005$ & -0.17 & NS \\
\hline$H$ & & & 0.76 & $<0.001$ & -0.12 & NS \\
\hline$M A$ & & & & & -0.47 & $<0.01$ \\
\hline \multicolumn{7}{|c|}{$\begin{array}{l}\text { 3LNO American } \\
\text { plaice }\end{array}$} \\
\hline$P_{\text {first }}$ & -0.50 & $<0.05$ & -0.66 & $<0.005$ & -0.07 & NS \\
\hline$H$ & & & 0.87 & $<0.001$ & -0.18 & NS \\
\hline$M A$ & & & & & -0.05 & NS \\
\hline
\end{tabular}

of the populations studied. It may be that the proportion of repeat spawners is only important under certain conditions. For example, in the Baltic, first time spawners make an important contribution to $R$ when the area of the Baltic suitable for cod reproduction is high (Cardinale and Arrhenius, 2000a).

Previous studies have used a variety of methods to explore the relationship between age composition and $R$ and have produced estimates of $S S B$ in a variety of ways. Many have assumed a specific functional relationship between $S S B$ and $R$ either through application of Ricker S-R models or through multiple linear regression (Marteinsdottir and Thorarinsson, 1998; O'Brien et al., 2003; Ottersen et al., 2006; Wigley, 1999; but see Cardinale and Arrhenius, 2000a,b). On the other hand, relating age composition directly to $R$ assumes that there is no effect of $S S B$ on $R$. We have made the explicit assumption that the number and/or weight of spawners should have some role in determining the level of $R$ (Brodziak et al., 2001; Myers and Barrowman, 1996). We removed this $S S B$ effect by fitting smoothers to the S-R data and relat- ing the residuals from these fits to age composition. In this way we hope to have avoided some of the spurious results that could arise from imposing an inappropriate S-R relationship either by applying a standard S-R relationship or incorporating S-R into multiple linear regression. In addition to this approach we have attempted to produce the best estimate of $S S B$ for these populations that we can by including estimates of female proportion mature-at-age and sex ratio-at-age. Not all populations have these data available and some studies have been forced to use constant (or year aggregated) maturity ogives and constant sex ratio. Some of the differences between our results and previous studies may be due to these differences in methodology.

S-R data tend to be noisy and the data in our study are no exception. This raises the possibility of being unable to detect an effect that is actually present. The statistical power of the tests performed here has yet to be determined. Simulation studies which include both density dependent effects and age composition effects would be useful in shedding light on this issue. Although 
such simulations would be fairly complex they would have general application to studies examining population data for any effects of age composition. In addition, there may be synergistic (or opposing) effects on $R$ of $P_{\text {first }}, H$ and $M A$. Analyses incorporating all the factors at once may have more power to detect a combined effect.

The characteristics of the individuals making up the spawning stock will clearly be important to $R$. Fecundity of individuals is not constant and variation will result in changes in total egg production (Köster et al., 2001; Marshall et al., 1998). Sex ratio and maturation are also variable (both are accounted for in this study) so that the number of adult females making up the spawning stock will change (Hunt, 1996; Jørgensen, 1990; Kraus et al., 2002; Marshall et al., 1998; Morgan and Colbourne, 1999; Rijnsdorp, 1989). Maternal condition will be important, influencing $R$ through effects on fecundity and/or viability of eggs and larvae, or even through skip spawning (DeMartini, 1991; Koslow et al., 1995; Lambert and Dutil, 2000; Marshall et al., 1998; Marteinsdottir and Steinarssson, 1998; Rideout et al., 2000). However, the importance of age composition of the spawning stock may not be universal. Studies have not always found an effect of $P_{\text {first }}$ on recruitment (Clemmesen et al., 2003; Wigley, 1999). The importance of age composition has also been found to depend on the size of the $S S B$ or to be enhanced under certain environmental conditions (Cardinale and Arrhenius, 2000a; Marteinsdottir and Thorarinsson, 1998; Ottersen et al., 2006). Further research is needed to explore under which conditions age composition exerts an important influence on $R$. Our results suggest that it may not be as widespread as commonly assumed.

\section{Acknowledgements}

We thank the many scientific staff and ships crew involved in the collection of the data used in this study. R. Rideout, M. Koen Alonso and two anonymous reviewers provided helpful comments on an earlier version of the manuscript.

\section{References}

BAROT, S., M. HEINO, M. J. MORGAN, and U. DIECKMANN. 2005. Maturation of Newfoundland American plaice (Hippoglossoides platessoides): longterm trends in maturation reaction norms despite low fishing mortality? ICES J. Mar. Sci., 62: 56-64. doi:10.1016/ j.icesjms.2004.10.004

BRATTEY, J., N. G. CADIGAN, B. P. HEALEY, G. R. LILLY, E. F. MURPHY, P. A. SHELTON, and J.-C. MAHE. MS 2004. An assessment of the cod (Gadus morhua) stock in NAFO Subdivision 3Ps in October 2004. CSAS Doc.
2004/083.

BRODZIAK, J. K. T., W. J. OVERHOLTZ, and P. J. RAGO. 2001. Does spawning stock affect recruitment of New England groundfish? Can. J. Fish. Aquat. Sci., 58: 306318. doi:10.1139/cjfas-58-2-306

BULMER, M. G. 1985. Selection for iteroparity in a variable environment. Amer. Nat., 126: 63-71. doi:10.1086/284396

CARDINALE, M., and F. ARRHENIUS. 2000a. The influence of stock structure and environmental conditions on the recruitment process of Baltic cod estimated using a generalized additive model. Can. J. Fish. Aquat. Sci., 57: 2402-2409. doi:10.1139/cjfas-57-12-2402

CARDINALE, M., and F. ARRHENIUS. 2000b. The relationship between stock and recruitment: are the assumptions valid? Mar. Ecol. Progr. Ser., 196: 305-309.

CLEMMESEN, C., V. BUHLER, G. CARVALHO, R. CASE, G. EVANS, L. HAUSER, W. F. HUTCHINSON, O. S. KJESBU, H. MEMPEL, E. MOKSNESS, H. OTTERAA, H. PAULSEN, A. THORSEN, and T. SVAASAND. 2003. Variability in condition and growth of Atlantic cod larvae and juveniles reared in mesocosms: environmental and maternal effects. J. Fish Biol., 62: 706-723. doi:10.1046/ j.1095-8649.2003.00060.x

DEMARTINI, E. E. 1991. Annual variations in fecundity, egg size, and the gonadal and somatic conditions of queenfish Seriphus politus (Sciaenidae). Fish. Bull., 89: 9-18.

DWYER, K. S., M. J. MORGAN, D. MADDOCK PARSONS, W. B. BRODIE, B. P. HEALEY, P. A. SHELTON, and H. MURUA. MS 2005. An assessment of American plaice in NAFO Divisions 3LNO. NAFO SCR Doc., No. 61, Serial No. N5147, 79 p.

GAVARIS, S. MS 1988. An adaptive framework for the estimation of population size. Can. Atlant. Fish. Sci. Advis. Comm. Res. Doc., 88/29.

HUNT, J. J. 1996. Rates of sexual maturation of Atlantic cod in NAFO Division 5Ze and commercial fishery implications. J. Northw. Atl. Fish. Sci., 18: 61-75.

JØRGENSEN, T. 1990. Long-term changes in age at sexual maturity of northeast Arctic cod (Gadus morhua L.). J. Cons. Inter. pour l'Explor. Mer, 46: 235-248.

KOSLOW, J. A., J. BELL, P. VIRTUE, and D. C. SMITH. 1995. Fecundity and its variability in orange roughy: effects of population density, condition, egg size, and senescence. J. Fish Biol., 47: 1063-1080. doi:10.1111/j.10958649.1995.tb06030.x

KÖSTER, F.W., H-H. HINRICHSEN, M.A. ST. JOHN, D. SCHNACK, B.R. MACKENZIE, J. TOMKIEWICZ, and M. PLIKSHS. 2001. Developing Baltic cod recruitment models. II. Incorporation of environmental variability and species interaction. Can. J. Fish. Aquat. Sci., 58: 15341556.

KRAUS, G., J. TOMKIEWICZ, and F. W. KÖSTER. 2002. Egg production of Baltic cod (Gadus morhua) in relation to variable sex ratio, maturity, and fecundity. Can. J. Fish. Aquat. Sci., 59: 1908-1920. doi:10.1139/f02-159

LAMBERT, T. C. 1990. The effect of population structure on recruitment in herring. J. Cons. Inter. pour l'Explor. Mer, 47: 249-255.

LAMBERT, Y., and J-D. DUTIL. 2000. Energetic consequenc- 
es of reproduction in Atlantic cod (Gadus morhua) in relation to spawning level of somatic energy reserves. Can. J. Fish. Aquat. Sci., 57: 815-825

MARSHALL, C. T., O. S. KJESBU, N. A. YARAGINA, P. SOLEMDAL, and Ø. ULLTANG. 1998. Is spawner biomass a sensitive measure of the reproductive and recruitment potential of northeast Arctic cod? Can. J. Fish. Aquat. Sci., 55: 1766-1783. doi:10.1139/cjfas-55-7-1766

MARSHALL, C. T., L. O'BRIEN, J. TOMKIEWICZ, F. W. KÖSTER, G. KRAUS, G. MARTEINSDOTTIR, M. J. MORGAN, F. SABORIDO-REY, J. L. BLANCHARD, D. H. SECOR, P. J. WRIGHT, N. V. MUKHINA, and H. BJORNSSON. 2003. Developing alternative indices of reproductive potential for use in fisheries management: case studies for stocks spanning an information gradient. J. Northw. Atl. Fish. Sci., 33: 161-190.

MARTEINSDOTTIR, G., and A. STEINARSSON. 1998. Maternal influence on the size and viability of Iceland cod Gadus morhua eggs and larvae. J. Fish Biol., 52: 12411258.

MARTEINSDOTTIR, G., and K. THORARINSSON. 1998. Improving the stock-recruitment relationship in Icelandic cod (Gadus morhua) by including age diversity of spawners. Can. J. Fish. Aquat. Sci., 55: 1372-1377. doi:10.1139/ cjfas-55-6-1372

MORGAN, M. J., and J. BRATTEY. 2005. Effect of changes in reproductive potential on perceived productivity of three Northwest Atlantic cod stocks. ICES J. Mar. Sci., 62: 6574. doi:10.1016/j.icesjms.2004.10.003

MORGAN, M. J., and E. B. COLBOURNE. 1999. Variation in maturity-at-age and size in three populations of American plaice. ICES J. Mar. Sci., 56: 673-688. doi:10.1006/ jmsc. 1999.0487

MYERS, R. A., and N. J. BARROWMAN. 1996. Is fish recruitment related to spawner abundance? Fish. Bull., 94: 707-724.

O'BRIEN, L., P. J. RAGO., R. G. LOUGH, and P. BERRIEN. 2003. Incorporating early-life history parameters in the estimation of the stock-recruit relationship of Georges Bank cod (Gadus moruha). J. Northw. Atl. Fish. Sci., 33: 191-205.

OLSEN, E. M., M. HEINO, G. R. LILLY, M. J. MORGAN, J. BRATTEY, B. ERNANDE, B., and U. DIECKMANN. 2004. Maturation trends indicative of rapid evolution preceded the collapse of northern cod. Nature, 428: 932-935. doi:10.1038/nature 02430

OTTERSEN, G., D. O. HJERMAN, and N. C. STENSETH.
2006. Changes in spawning structure strengthen the link between climate and recruitment in a heavily fish cod (Gadus morhua) stock. Fish. Oceanogr., 3: 230-243. doi:10.1111/j.1365-2419.2006.00404.X

POWER, D., B. P. HEALEY, E. F. MURPHY, J. BRATTEY, and K. DWYER. MS 2005. An assessment of the cod stock in NAFO Divisions 3NO. NAFO SCR Doc., No. 67, Serial No. N5154, 40 p.

RICKER, W. E. 1954. Stock and recruitment. J. Fish. Res. Bd. Canada, 11: 559-623.

RIDEOUT, R. M., M. P. M. BURTON, and G. A. ROSE. 2000. Observations on mass atresia and skipped spawning in northern Atlantic cod, from Smith Sound, Newfoundland. J. Fish Biol., 57: 1429-1440. doi:10.1111/j.10958649.2000.tb02222.x

RIJNSDORP, A. D. 1989. Maturation of male and female North Sea plaice (Pleuronectes platessa L.). J. Cons. Inter. pour l'Explor. Mer, 46: 35-51.

SECOR, D. H. 2000. Spawning in the nick of time? Effect of adult demographics on spawning behaviour and recruitment in Chesapeake Bay striped bass. ICES J. Mar. Sci., 57: 403-411.

SEGER, J., and H. J. BROCKMAN. 1987. What is bet hedging? In: Oxford Surveys in Evolutionary Biology 4. P. H. Harvey and L. Partridge (eds.). Oxford University Press, Oxford, UK, p. 182-211.

SHELTON, P. A. 1992. The shape of recruitment distributions. Can. J. Fish. Aquat. Sci., 49: 1754-1761.

SHELTON, P. A., and G. R. LILLY. 2000. Interpreting the collapse of the northern cod stock from survey and catch data. Can. J. Fish. Aquat. Sci., 57: 2230-2239. doi:10.1139/cjfas-57-11-2230

SOLEMDAL, P., O. KJESBU, and M. FONN. MS 1995. Egg mortality in recruit- and repeat-spawning cod- an experimental study. ICES CM Doc., G:35, 14 p.

TRIPPEL, E. A. 1998. Egg size and viability and seasonal offspring production of young Atlantic cod. Trans. Amer. Fish. Soc., 127: 339-359. doi:10.1577/15488659(1998) $127<0339$ :ESAVAS $>2.0 . \mathrm{CO} ; 2$

TRIPPEL, E. A., O. S. KJESBU, and P. SOLEMDAL. 1997. Effects of adult age and size structure on reproductive output in marine fishes. In: Early life history and recruitment in fish populations. R. C. Chambers and E. A. Trippel (eds.). Chapman and Hall, London, p. 31-62.

WIGLEY, S. E. 1999. Effects of first-time spawners on stockrecruitment relationships for two groundfish species. $J$. Northw. Atl. Fish. Sci., 25: 215-218. 